\title{
Identidade sociolinguística na fronteira de Aceguá (Brasil-Uruguai)
}

\section{Sociolinguistic identity in the borderland of Aceguá (Brazil-Uruguay)}

Cintia da Silva Pacheco

$\mathrm{UnB}$

cintialetras@yahoo.com.br

Resumo: O objetivo desta pesquisa é identificar e analisar a entrada do pronome a gente na comunidade bilíngue uruguaia em Aceguá (fronteira Brasil-Uruguai) como um elemento ratificador da variedade do português uruguaio da fronteira. Essa mudança linguística é recente no português uruguaio, mesmo porque até então não havia registros de a gente como pronome, mas apenas como item lexical, semelhante ao que acontece no espanhol. A análise é sobre a identidade sociolinguística da fronteira a partir da inserção do pronome a gente na comunidade uruguaia como sujeito discursivo brasileiro sem ferir a identidade múltipla e fluida dos moradores da fronteira.

Palavras-chave: contato linguístico; português uruguaio; português brasileiro; pronome a gente; identidade sociolinguística.

Abstract: This research aims to identify and analyze the use of $a$ gente pronoun in Uruguayan bilingual community of Aceguá (BrazilianUruguayan border), like a phenomenon that ratifies the Uruguayan Portuguese variety spoken in the borderland. This linguistic change 
is recent in the Uruguayan Portuguese, considering that there were no previous records of the use of $a$ gente as a pronoun, but only as a lexical item, resembling what happens in the Spanish case. This analysis is about the sociolinguistic identity in the borderland, mainly from the insertion of a gente pronoun as a Brazilian discursive subject in the Uruguayan community, without hurting the multiple and fluid identity of the borderland neighbors.

Keywords: linguistic contact; Uruguayan Portuguese; Brazilian Portuguese; a gente pronoun; sociolinguistic identity.

Recebido em 14 de setembro de 2015. Aprovado em 01 de fevereiro de 2016.

A identidade dá-nos a ideia de quem somos e de como nos relacionamos com os demais e com o mundo em que vivemos. Ela marca as formas em que somos iguais aos outros que compartilham dessa posição, bem como as formas em que somos diferentes daqueles que não compartilham da nossa posição. Frequentemente, a identidade é mais claramente definida pela diferença, isto é, por aquilo que não é. Identidades podem estar marcadas pela polarização, por exemplo, nas maneiras mais extremas de conflito nacional ou étnico, pela marca de inclusão ou exclusão - estrangeiros e nativos, "nós" e "eles". As identidades frequentemente são construidas na forma de oposições tais como homem/mulher, negro/branco, hétero/ gay, saudável/não saudável, normal/anormal.

(WOODWARD, 1997, p. 1-2, tradução nossa ${ }^{1}$ )

\footnotetext{
${ }^{1}$ No original: "Identity gives us an Idea of who we are and of how we relate to others and to the world in which we live. Identity marks the ways in which we are the same as other who share that position, and the ways in which we are different from those who do not. Often, identity is most clearly defined by difference, that is by what it is not. Identities may be marked by polarization, for example in the most extreme forms of national or ethnic conflict, and by the marking of inclusion or exclusion - insiders and outsiders, 'us' and 'them'. Identities are frequently constructed in terms of oppositions such as man/woman, black/white, straight/gay, healthy/unhealthy, normal/deviant”.
} 


\section{Introdução}

O objetivo desta pesquisa é identificar a identidade sociolinguística, analisar a entrada do pronome a gente na comunidade bilíngue uruguaia em Aceguá (fronteira Brasil-Uruguai) e verificar se esse fenômeno constitui um elemento ratificador da variedade do português uruguaio da fronteira e se aproxima do português brasileiro da fronteira e do restante do Brasil.

A hipótese principal é de que se trata de uma mudança linguística recente na variedade do português uruguaio, mesmo porque até então não havia registros de a gente como pronome, mas apenas como item lexical, semelhante ao que acontece no espanhol (ELIZAINCÍN, 1987, p. 85).

O marco teórico da pesquisa é a Teoria da Variação, proposta por Labov em $1972^{2}$, e a Teoria da Mudança Linguística, desenvolvida por Weinreich, Labov e Herzog em 1968 ${ }^{3}$. A análise quantitativa dos dados, obtidos por meio de entrevistas, é feita através do novo pacote de programas Goldvarb-X (SANKOFF, 1988a; SANKOFF, TAGLIAMONTE; SMITH, 2005).

O resultado estatístico indica que, no nível linguístico e social, o português brasileiro e o português uruguaio (sem os falantes categóricos de nós) são semelhantes quanto ao favorecimento do pronome sujeito a gente nos contextos de: (i) faixa etária jovem, (ii) sujeito explícito, (iii) referência genérica, (iv) dados de a gente precedidos de a gente, (v) tempo verbal do presente.

$\mathrm{O}$ resultado aponta para uma diferença social, já que a análise uruguaia com todos os falantes mostra os adultos favorecendo o uso de a gente por questões de mobilidade social e pela existência de falantes categóricos. Portanto, os resultados obtidos apontam semelhanças e diferenças importantes nas duas comunidades de fala da fronteira BrasilUruguai, que as aproximam e as individualizam.

A análise é fundamentada com uma discussão sobre a identidade sociolinguística da fronteira a respeito da inserção do pronome a gente na comunidade uruguaia como sujeito discursivo sem ferir a identidade múltipla e fluida dos moradores da fronteira.

${ }^{2}$ Cf. Labov (2008).

${ }^{3} \mathrm{Cf}$. Weinreich, Labov e Herzog (2006). 


\section{A identidade sociolinguística}

Labov (2008) define a comunidade de fala como um grupo de falantes que compartilham o mesmo sistema linguístico e um conjunto de normas sociais. Para a comunidade fronteiriça de Aceguá, como seria a delimitação dessa norma? No caso dos uruguaios, trata-se, em sua grande maioria, de duas normas linguísticas (espanhol e português) e no caso dos brasileiros trata-se, em sua grande maioria, de uma única norma (português). No entanto, em termos sociais e identitários, as normas são frequentemente compartilhadas na comunidade de fala da fronteira de Aceguá. Para tanto, foram entrevistados 38 colaboradores, distribuídos da seguinte maneira:

Tabela 1 - Constituição geral do corpus

\begin{tabular}{l|l|l}
\hline Faixa etária & Brasileiros & Uruguaios \\
\hline \multirow{2}{*}{$\mathbf{1 5}$ a 30 anos } & 4 homens & 3 homens \\
& 3 mulheres & 4 mulheres \\
\hline \multirow{2}{*}{$\mathbf{3 1}$ a 49 anos } & 2 homens & 6 mulheres \\
\hline \multirow{2}{*}{ Acima de 50 anos } & 5 mulheres & 2 homens \\
\hline TOTAL & 2 mulheres & 4 mulheres \\
\hline
\end{tabular}

Fonte: Pacheco (2014)

Assim, segundo Scherre (2006), o aspecto social (estratificação, estilo e avaliações subjetivas), na perspectiva laboviana, é um dos elementos de natureza externa à estrutura que ajuda a compreender a variação e a mudança linguística. O sentimento de pertencimento a uma ou outra comunidade de fala varia conforme a perspectiva dos próprios falantes.

Em observações participantes, nota-se que os brasileiros da fronteira se sentem geralmente pertencentes a uma só comunidade de fala brasileira, mas os uruguaios da fronteira geralmente se sentem pertencentes à comunidade de fala brasileira e uruguaia, ora com tendência maior para a comunidade brasileira ora para a uruguaia, como o caso dos jovens uruguaios colaboradores desta pesquisa.

É perceptível que ambos os lados da fronteira compartilham uma norma linguística, o português, e, portanto, constituem uma comunidade 
linguística definida pelos sujeitos de "mesmo" discurso identitário quando estão falando em português ou quando tentam se aproximar do português brasileiro utilizando o pronome $a$ gente.

Com relação à variação pronominal de primeira pessoa do plural, os resultados linguísticos e sociais são semelhantes, o que confirma que a comunidade de Aceguá partilha normas linguísticas e sociais da fronteira. Do ponto de vista social, os jovens uruguaios favorecem o emprego do pronome a gente apenas com a retirada dos dados categóricos de nós. Por isso, é de suma importância investigar que tipo de relação identitária se manifesta na comunidade, de ambos os lados da fronteira, e no próprio indivíduo.

Tabela 2 - Frequência geral dos colaboradores de Aceguá

\begin{tabular}{l|c|c|c|c}
\hline & \multicolumn{2}{|c|}{ Com todos } & \multicolumn{2}{c}{ Sem os categóricos } \\
\hline Colaboradores & A gente & Nós & A gente & Nós \\
\hline \multirow{2}{*}{ Brasileiros e uruguaios } & $45,1 \%$ & $54,9 \%$ & $58,3 \%$ & $41,7 \%$ \\
& $452 / 1002$ & $550 / 1002$ & $452 / 775$ & $323 / 775$ \\
\hline \multirow{2}{*}{ Uruguaios } & $29,3 \%$ & $70,7 \%$ & $49,1 \%$ & $50,9 \%$ \\
& $135 / 461$ & $326 / 461$ & $135 / 275$ & $140 / 275$ \\
\hline \multirow{2}{*}{ Brasileiros } & $58,6 \%$ & $41,4 \%$ & $63,4 \%$ & $36,6 \%$ \\
& $317 / 541$ & $224 / 541$ & $317 / 500$ & $183 / 500$ \\
\hline
\end{tabular}

Fonte: Pacheco (2014)

$\mathrm{Na}$ análise com todos os dados, os uruguaios alcançam 29,3\% no uso de $a$ gente e os brasileiros, $58,6 \%$. Na análise sem os dados categóricos de nós, há um aumento significativo do uso de a gente para os uruguaios $(49,1 \%)$ e para os brasileiros $(63,4 \%)$. Essa diferença percentual entre as análises, por conta da manifestação linguística individual, é também uma motivação para analisar a identidade dos colaboradores da fronteira de Aceguá, sobretudo, dos uruguaios que fazem parte dos $29,3 \%$. Assim também é possível entender melhor porque alguns colaboradores uruguaios usam categoricamente o nós.

Labov (2008) já tratava da questão da identidade no caso de Martha's Vinneyard, em que situa bem o que é aceito localmente e o que é visto como de fora da ilha; a segregação em guetos dos adolescentes afro-americanos em Nova Iorque a partir do apartheid social; e etnias judaicas eítalo-americanas em Nova Iorque que entram em contato com a língua dominante. 
Sobre Martha's Vinneyard, Labov (2008) identificou que os que planejavam ficar na ilha exibiam maior centralização no uso dos ditongos (ay) e (aw) do que os que planejavam deixar a ilha. Inclusive o grupo dos portugueses que se identificavam mais com a ilha também exibia maior centralização do que os descendentes de ingleses, já que os portugueses afirmavam seu status de vineyardenses nativos com a realização de um traço linguístico também específico da comunidade de Martha's Vineyard, demonstrando uma atitude positiva para com a ilha.

Dessa forma, há semelhança entre Martha's Vineyard e Aceguá no tocante à constituição urbana e rural de ambas as comunidades, bem como à motivação para o uso ou não da variante inovadora. Os falantes uruguaios que usam categoricamente nós têm redes sociais mais restritas ao Uruguai, sem muito contato com o Brasil, e demonstram uma identidade mais uruguaia, com poucos elementos brasileiros. É parecido com os falantes nativos da ilha de Martha's Vineyard que demarcam sua identidade cultural com a alta centralização dos ditongos, como forma de marcar um sentimento de pertencimento à ilha.

A presença do pronome a gente pode estar associada à aproximação do modo de falar e viver tipicamente brasileiro, mesmo que de forma inconsciente, contrariamente ao que acontece em Martha's Vineyard, em que a alta centralização dos ditongos (ay) e (aw) estava relacionada à grande resistência às incursões dos veranistas, ou seja, com os que vêm de fora.

Logo, em Aceguá o pronome a gente não parece ser interpretado como um padrão vindo de fora que precise ser combatido. Pela própria identificação com o Brasil e com o fato de muitos também serem brasileiros, essa reação é menos segregadora. Para Labov (2008, p. 43), "somente quando se atribui significado social a tais variações é que elas são imitadas e começam a desempenhar um papel na língua. A regularidade, portanto, vai ser encontrada no final do processo".

Por se tratar de uma mudança linguística rumo ao uso cada vez maior de um pronome (a gente) inovador, prestigiado, prototípico do português monolíngue, brasileiro e dos jovens, é importante discutir os conceitos labovianos de change from below (mudança sem consciência social) e change from above (mudança com consciência social) (LABOV, 2001, 2008).

A mudança sem consciência social ou change from below seria interna e natural à própria variedade linguística em questão, como é o caso do português brasileiro da fronteira, uma vez que o a gente já pertencia 
à língua desde o português arcaico e se gramaticalizou em pronome. No caso do português uruguaio da fronteira, a mudança parece acontecer mais com consciência social ou change from above, uma vez que o pronome a gente ainda não havia sido registrado nesse falar uruguaio e é um ideal prestigiado, urbano e típico da variedade monolíngue brasileira, sendo, portanto, externo à variedade em uso.

Com uma interpretação menos polarizada e mais relativizada, a variação pronominal de primeira pessoa do plural também pode refletir uma mudança sem consciência em ambos os lados da fronteira, visto que se trata provavelmente de um fenômeno não estigmatizado (ZILLES, 2007) tanto no português uruguaio como no português brasileiro da fronteira em Aceguá. A partir da inserção de a gente no português uruguaio, o pronome começa a avançar e expandir de forma natural nas mesmas variáveis linguísticas e sociais conforme acontece no português brasileiro.

No caso da fronteira, será que a identidade é mais brasileira, mais uruguaia ou são híbridas e fluidas? Como a identidade sociolinguística é formada e constituída na fronteira e de que forma ela interfere no falar local e na escolha dos pronomes de primeira pessoa do plural? Todos esses questionamentos se intensificam depois dos resultados estatísticos que apontam que o sistema linguístico e social é, em grande parte, semelhante na comunidade de Aceguá como um todo, em ambos os lados da fronteira. Assim, é importante analisar também as questões mais subjetivas para entender mais e melhor as múltiplas identidades que se manifestam no momento da interação entre os falantes da fronteira.

Para responder a essas perguntas, é preciso entender como o bilinguismo, a territorialidade, a ecolinguística local, a nacionalidade, o processo de urbanização, a identidade, a alteridade, a pós-modernidade, os discursos identitários e os significados sociais das variantes se manifestam na fronteira.

\section{As identidades, os territórios e a Ecolinguística}

Do ponto de vista do bilinguismo, admite-se que os uruguaios utilizam como línguas maternas o português e o espanhol, já que dominam as duas igualmente, ainda que as utilizem em contextos sociais diferentes. Segundo Uyeno (2003, p. 40-41), "língua materna é a que se domina mais e é normalmente falada em casa, tem a ver com a terra onde nasceu, a herança sanguínea e a língua na qual é criado". No entanto, não se 
trata de apenas conviver com as duas línguas, mas de necessariamente utilizá-las na prática interativa e comunicativa.

Do ponto de vista ecológico, segundo a teoria da Ecolinguística (COUTO, 2007, 2009b), a língua é analisada juntamente com o meio ambiente. De acordo com o autor, "para que haja uma língua (L) é necessário haver um povo ou população (P) que a forme e use, sendo que esse povo tem que viver e conviver em determinado lugar ou território (T)". Essa totalidade é conhecida como comunidade (COUTO, 2009b, p. 19).

Para Couto (2009b), um dos tipos de contato linguístico seria a situação fronteiriça vista como o reflexo de dois povos e dois territórios. No caso de Aceguá, o lado uruguaio utiliza predominantemente o português, ainda que alterne com o espanhol, e o lado brasileiro utiliza o português. De acordo com o autor, "quando uma língua tem mais prestígio, tende a ser mais usada nas interações interlinguísticas." (Ibid., 2009 b, p. 54). Como nessa fronteira não há nenhum acidente geográfico, "o mais comum é haver algum tipo de convergência linguística" (Loc. cit.). Essa convergência não é nenhuma espécie de "portunhol", mas a predominância do português da região em ambos os lados da fronteira ou de formas linguísticas típicas do português brasileiro.

No caso do Brasil-Uruguai, os conquistadores desse território foram os portugueses e espanhóis. Com a dizimação das línguas indígenas, passa a prevalecer o português em ambos os lados da fronteira independentemente da divisão política dos territórios. Quando há conquistas e a dominação de povos, frequentemente os detentores do poder delimitam artificialmente determinado território como sendo do Estado, o que inclui o povo e a língua, ignorando os minoritários ou mais fracos (Ibid., 2009b, p. 113-114).

No início do processo de territorialização com povos e línguas diferentes, concebe-se uma sociedade, bilíngue ou multilíngue, e depois tenta-se a todo custo transformá-los numa única nação, com uma única língua e com uma única identidade.

A delimitação de uma região multilíngue traz implicações políticas, culturais e educacionais, como políticas e planejamentos linguísticos centralizadores que privilegiam a língua estatal, discursos oficiais, publicações e meios de comunicação de massa. A língua estatal não significa língua da nação ou do povo como um todo, porque cada povo é uma nação, por mais que se queira ter uma nação ideal, homogênea e, sobretudo, artificial (Ibid., 2009b p. 130). 
A verdade é que o sentido de nação é uma construção imaginária efêmera e errônea por projetar uma história e uma cultura homogêneas (DEALTRY, 2002) na relação direta entre identidade nacional e comunidade imaginada (WOODWARD, 1997, p. 18). A língua oficial ou estatal também é, de certa forma, uma língua imaginada, porque não existe enquanto manifestação linguística real.

A fronteira é um excelente exemplo de uma situação linguística altamente heterogênea. Por conta de todos os fatores intrínsecos à situação fronteiriça, bilíngue e de múltiplas identidades, devemos considerá-la ora como uma única comunidade de fala brasileira, a partir da convergência com o uso do português e com o uso do pronome a gente na tentativa de aproximação com o português brasileiro, ora como duas comunidades de fala quando do lado uruguaio se utiliza o espanhol e do lado brasileiro, o português. Do ponto de vista da nação, são duas nações, mas do ponto de vista linguístico e interacional ora os sujeitos se colocam como distintos, ora como pertencentes a uma mesma comunidade. Assim, partilham de normas sociais comuns aos dois lados da fronteira. A situação fronteiriça em Chui/Chuy é de

um único ecossistema, mesmo que transicional, entre dois outros ecossistemas maiores, ou seja, trata-se de uma única comunidade de fala. Um dos principais argumentos é o de que há uma comunidade entre os dois lados (só uma avenida separa Brasil e Uruguai); uma vista aérea nos revela uma única cidade. Um segundo argumento é a atitude dos membros da comunidade. Para eles é "uma coisa só". Quem mora de uma lado não considera o morador do outro lado da avenida como alguém de "outra" cidade. (COUTO, 2009a, p. 14, grifo do autor).

Isso também acontece com Aceguá. A diferença principal das duas fronteiras é que em Chuy o espanhol é a língua predominante e em Aceguá é o português, o que nos leva a entender, do ponto de vista linguístico e identitário, que ora a comunidade uruguaia interage em português, ora em espanhol, enquanto a brasileira predominantemente em português. Essa alternância entre as línguas pode ser consequência de aproximações identitárias múltiplas que acontecem na fronteira, dependendo do interlocutor, do grau de intimidade, do assunto da conversa, da proximidade com as línguas ou os países. 
Com relação aos resultados linguísticos e sociais, de maneira geral, a comunidade se manifesta de forma mais convergente. Interessante retomar a diferença que houve com os resultados sociais com e sem os dados categóricos do pronome nós. Na análise brasileira, tanto com ou sem os dados categóricos, o padrão da faixa etária foi o mesmo: jovens favorecendo o uso de a gente. Já na análise uruguaia com todos os colaboradores, os adultos favoreciam o emprego de a gente e os jovens e os de mais idade favoreciam o uso de nós. Ao analisar cada falante isoladamente, percebeuse que parte desses jovens apresentou um uso categórico de nós porque não tinham contato com o Brasil, eram mais voltados para o Uruguai e, portanto, tinham menos mobilidade social e geográfica que os demais. Retirando esses casos categóricos, o padrão da faixa etária se manifesta igualmente à análise dos dados de falantes brasileiros, mostrando a força do condicionamento social semelhante na fronteira.

O padrão etário, resultado da análise com todos os falantes em que adultos favorecem o emprego de $a$ gente, e da análise sem os casos categóricos, com jovens também favorecendo o a gente, também mostra como as comunidades de fala são permeadas pelas identidades múltiplas dos grupos e dos indivíduos.

A tendência ao polo brasileiro acontece, diacronicamente, devido à influência histórica dos portugueses na região e, sincronicamente, devido à presença massiva do português monolíngue como língua dominante, mais urbana, de maior prestígio econômico, social, político e comercial. Assim, a fronteira política não coincide com a fronteira linguística, porque aquela é artificial e esta, natural. O que é natural certamente varia e muda ao longo do tempo, diferentemente do estático e convencionado.

Qualquer comunidade existe em um tempo materializado em um espaço. Assim, é também importante analisar a fronteira a partir da geografia, como de certa forma trabalha a Ecolinguística. Para Haesbaert (2002, p. 31), o tempo e o espaço geográfico não estão desaparecendo, mas surgindo sob novas formas e novos significados. Essa ideia é reforçada por Bauman (2001, p. 15) para quem "a modernidade começa quando o espaço e o tempo são separados da prática da vida e entre si", uma vez que antigamente eram estáveis e se correspondiam biunivocamente.

Para definir território, segundo Haesbaert (2002, p. 35), há três linhas de pensamento: a primeira vê o território do ponto de vista 
econômico como "base material, concreta, de reprodução da sociedade". A sociedade, assim, será mais territorializada quanto mais for dependente das bases materiais como as sociedades indígenas. E quanto maior a tecnologia, maior a desterritorialização, que seria o fim das distâncias geográficas e o desapego do meio físico com o ciberespaço (LÉVY, 1999). A ordem econômica da globalização também faz parte dessa interpretação, uma vez que a mobilidade espacial é maior e as grandes empresas se sobrepõem aos comércios locais (HAESBAERT, 2002, p. 36).

A segunda linha vê o território do ponto de vista político, do poder das instituições como forma de controle dos indivíduos. "Mas aqui também são muitos os que defendem a tese da desterritorialização: a globalização, suprimindo cada vez mais as fronteiras, estaria enfraquecendo o controle do Estado-nação, território por excelência da modernidade" (Ibid., p. 37).

A terceira abordagem é o território a partir da dimensão cultural, dotado de identidade territorial (étnica, nacional, religiosa, dos grupos sociais). Mesmo assim, a cultura não pode ser vista independentemente da concepção política, "porque a produção simbólica que domina o nosso tempo é indissociável das relações de poder às quais está ligada. Assim, mesmo os geógrafos que destacaram a tradição política do território não ignoram suas bases culturais, simbólicas" (Loc. cit.). É na perspectiva de cultura política, ao mesmo tempo material e simbólica, que Haesbaert lida com os processos de desterritorialização.

Hoje, na desordem territorial denominada precariamente de pós-moderna, lado a lado com uma globalização que se diz homogeneizadora e niveladora de culturas, surge uma fragmentação envolvendo territórios estatais-nacionais, com um caráter político mais pronunciado, e territórios de forte conotação identitária. (HAESBAERT, 2002, p. 39).

Essa desterritorialização pressupõe necessariamente uma reterritorialização (reconstrução territorial), uma vez que a ecolinguística já resguarda a tríade "povo, língua e território" (COUTO, 2007, 2009b) a partir das formas de organização. Há, portanto, um distanciamento ou alongamento espaço-temporal, no qual o local se alonga ou desencaixa para atingir o global (HAESBAERT, 2002, p. 33). Esse global, em Aceguá, é a aproximação cada vez maior do Brasil e do português. Segundo Haesbaert (2002, p. 41), 
teríamos territórios culturalmente mais fechados, cujos grupos poderiam ser vistos, ao mesmo tempo, como territorializados (internamente) e desterritorializantes (na relação com grupos de outros territórios, deles excluídos), e territórios culturalmente mais híbridos, no sentido de permitirem/facilitarem o diálogo intercultural, quem sabe até possibilitando a emergência de novas formas, múltiplas, de identificação social.

Em Aceguá, ora a comunidade é mais territorializada (por exemplo, no comportamento categórico de alguns jovens uruguaios no uso apenas de nós como pronome de primeira pessoa do plural, também pela pouca proximidade com o Brasil), ora desterritorializada, quando não se percebem diferenças sociais nas análises sem os casos categóricos, mantendo o padrão etário jovem como favorecedor do emprego do pronome a gente. A autenticidade cultural tradicionalmente correspondia a um território de fronteiras bem definidas. Hoje, a identidade é híbrida e inautêntica (Ibid., p. 46). Isso quer dizer que não há nada homogêneo quando se trata de fronteiras, cultura, identidade.

As territorializações são "efetivamente múltiplas, resultantes da sobreposição de funções e controles, como nas novas formas de gestão multiescalares em que começam a se conjugar níveis locais, regionais, nacionais, megarregionais (ou de blocos) e globais" (Ibid., p. 48). Desse modo, um único indivíduo é capaz de vivenciar (dependendo da classe social e do contato com o Brasil) diversas territorialidades, assim como diversas identidades, mesmo estando em um único local físico que é dividido apenas politicamente. Essa territorialidade é simbolicamente vivida, mesmo não sendo necessariamente concreta ou física.

Um território múltiplo, onde devemos implementar não uma identidade una e pouco permeável ou, ao contrário, a diluição de todas as identidades, mas o convívio entre várias construções identitárias, inclusive aquela que envolve a opção de compartilhar múltiplos territórios. (HAESBAERT, 2002, p. 49).

O território múltiplo é associado à questão da nacionalidade, da identidade múltipla e do bilinguismo. Por isso, o português é visto 
politicamente no Brasil como língua nacional, e a defesa da unidade da língua como unidade nacional depende da instrução e da escolarização para a nacionalização do ensino e, consequentemente, da língua no estado do Rio Grande do Sul (TRINDADE, 2002, p. 238-239).

Todas essas estratégias governamentais evidenciam que a nação brasileira era constituída de culturas diversas, havendo inclusive o controle governamental do número de casamentos e de filhos entre brasileiros e entre brasileiros e outras nacionalidades, e que o processo de unificá-la envolveu conquista violenta, pois ocasionou, por vezes, a supressão forçada das diferenças culturais e sua tradução pela mescla de identidades, com os governantes intervindo nas escolas - fechando-as e demitindo professores (as) - e obrigando o uso de uma única língua. Pode-se constatar, ainda, como se dava essa imposição, examinando-se o jogo de forças - ser brasileiro(a) ou ser estrangeiro(a): falar a língua de origem ou falar a língua nacional - em que se defrontam internamente pessoas e grupos, com suas diversidades étnicas. (Ibid., p. 241).

No Uruguai, a língua espanhola é fator identitário do uruguaio. Ainda que nessa última década as políticas bilíngues estejam mais em voga, se o uruguaio fala português, sua identidade é enfraquecida por esse discurso nacional de que no Uruguai se fala espanhol e que ser uruguaio pressupõe a fala espanhola (CARVALHO, 2006). Nessa situação, como fica a identidade do fronteiriço, sobretudo do uruguaio bilíngue? Há alguma relação direta entre identidade, nacionalidade e uso linguístico?

\section{As identidades e as nacionalidades}

A língua materna é falada primeiramente no espaço familiar. Assim, ao estabelecer uma língua oficial, o Estado ignora a língua das minorias e não prevê as diferenças linguísticas e sociais em todo o território brasileiro.

A identidade nacional representa uma cultura nacional, apenas como construção discursiva. De acordo com Trindade (2002, p. 247), "vistas como discursos, as culturas nacionais correspondem a modos de construir sentidos, que influenciam e organizam tanto nossas ações quanto a concepção que temos de nós mesmos". 
As culturas nacionais não deixam, portanto, de contribuir para a construção das nossas identidades, mas também não têm relação direta e única, porque, inclusive, alguns colaboradores de Aceguá diziam que eram brasileiros e depois, no meio da entrevista, diziam que eram uruguaios também, e vice-versa. Ou seja, muitas vezes eles tinham as duas nacionalidades, mas se identificavam primeiro com apenas uma, e depois se lembravam de que também tinham outra.

A identidade cultural como identidade nacional também é fragmentada na modernidade tardia, por isso, é difícil para os fronteiriços definirem, muitas vezes, se são uruguaios ou brasileiros. Segundo Hall (2005, p. 48), "as identidades nacionais não são coisas com as quais nós nascemos, mas são formadas e transformadas no interior da representação".

Como exemplo disso, temos dois falantes: uma jovem uruguaia (também com nacionalidade brasileira), filha de mãe uruguaia e pai brasileiro; e um jovem brasileiro, filho de pais brasileiros. A menina não consegue se enquadrar em apenas uma nacionalidade:

Entrevistadora: Mas o primeiro registro foi em que?

Entrevistada: Brasileiro. Mas é como tudo, eu tenho a documentação uruguaia. O pessoal da fronteira é enrolado, o pessoal da fronteira tem os dois documentos, entende? Então eu não tenho como dizer eu sou só brasileira. Eu sou brasileira e sou uruguaia ao mesmo tempo.

Entrevistadora: Se bem que ficar como brasileiro... por exemplo, quando eu te pergunto tu te identifica primeiro como uruguaia ou como brasileira assim?

Entrevistada: Como brasileira.

Entrevistadora: Como brasileira?

Entrevistada: Como brasileira, sim. Por isso que eu te digo que eu tenho dois documentos, e toda vida estudei no Uruguai, e se eu tivesse que abrir mão de um documento, pra mim seria difícil. Por quê? Porque eu sou brasileira. E dizia: mas não, eu sou brasileira, nasci no Brasil, sou brasileira, quero o Brasil, e eu sou brasileira. Mas os meus estudos, a minha carreira, tudo o que eu fiz, tá tudo no Uruguai, eu não posso abrir mão do Uruguai. Mas a mim me dói se eu tenho que abrir mão do Brasil, entende?

(CAR, mulher, de 15 a 30 anos, uruguaia, ensino médio). 
Assim, a entrevistada diz que é brasileira e uruguaia ao mesmo tempo, porque tem necessidade de legitimação do Estado, mas afirma que se identifica mais com o Brasil porque nasceu lá, ainda que não consiga abrir mão do Uruguai, onde se dedicou aos estudos e à carreira. Suas identidades são múltiplas ou, no caso dessa fronteira, duplas, fragmentadas e também construídas no momento da interação quando fala que sente "dor" por ter de abrir mão de alguma nacionalidade.

No caso do jovem brasileiro, ele não se identifica muito com os costumes da fronteira e manifesta gostos mais gerais, globalizados, externos à comunidade, como o gosto por pagode.

Entrevistadora: Pois é, seria ótimo. Aí, o que você conseguir, prA GENTE vai ser bom. Vocês vão participar dos festejos ai da Semana Farroupilha?

Entrevistado: É, frequento. Não é muito o meu...

Entrevistadora: É? Não se identifica muito não?

Entrevistado: Não é muito meu gosto. É, não.

Entrevistadora: É mesmo? Achei que era super...

Entrevistado: Apesar de ser daqui...

Entrevistadora: Eu achei que era geral.

Entrevistado: É. Mesmo sendo daqui, música gaúcha aí, no ritmo uruguaio que é a Cúmbia... não consigo gostar.

Entrevistadora: É mesmo?

Entrevistado: Sou mais pagodeiro.

Entrevistadora: Ah, é?

Entrevistado: Sou mais pagodeiro.

(GUI, homem, de 15 a 30 anos, brasileiro, ensino médio).

Dessa forma, o jovem demonstra certa distância da Semana Farroupilha, uma festa típica do Sul do Brasil e já enraizada também na fronteira, compartilhada pela maioria dos uruguaios e brasileiros. Esse falante, independentemente da nacionalidade e do território onde mora, diverge em algumas normas sociais da comunidade, ou seja, não há sentimento de pertença ao grupo cultural brasileiro.

A nação, além de uma entidade política, é um sistema de representação cultural. Segundo Hall (2005, p. 50), "as pessoas não são apenas cidadãos/ãs legais de uma nação; elas participam da ideia de uma nação tal como representada em sua cultura nacional". As identidades 
nacionais também já foram mais unificadas, mas agora estão sendo deslocadas por causa dos processos de globalização (Loc. cit.).

Para Hall (2005), é necessário levar em consideração as estratégias discursivas para a construção de uma comunidade imaginada: memórias do passado, desejo por viver em conjunto e perpetuação da herança nacional. A cultura nacional é também um discurso, porque é o modo de construir e dar sentido às nossas ações e ao que somos nós. Ao produzir sentido sobre a "nação", constroem-se identidades que podem identificar os sujeitos ou não (Ibid., p. 50-51). A identidade nacional é baseada na ideia de um único povo, mesmo que nem todos participem da mesma forma na sociedade, uma vez que as nações modernas são híbridos culturais (Ibid., p. 55, 62).

Em Aceguá, a nacionalidade e a identidade sociolinguística estão imbricadas, o que impede qualquer tentativa de separação rígida entre os dois países, ou seja, não basta oficialmente ser uruguaio ou ser brasileiro para haver correspondência direta com a cultura, a identidade e a língua desse país. Muito pelo contrário, pois as relações identitárias na fronteira perpassam a simples nacionalidade, sobretudo do lado uruguaio, uma vez que são bilíngues e as relações bem heterogêneas. Por isso, fizemos três análises, uma da comunidade como um todo, uma do lado uruguaio e outra do lado brasileiro, interpretando ora a identidade cultural geral, ora fragmentada em uruguaio ou brasileiro.

\section{As identidades e as diferenças}

Para Uyeno (2003, p. 40-41), “é questionável a homogeneização como fundamento de uma identidade 'autêntica', tanto em termos individuais como comunitários, tanto como a ideia de nação, ou nacionalidade, como um fato, um dado real". Os processos identitários são mais flexíveis e híbridos e a heterogeneidade faz parte da vivência social. A materialização da identidade se dá a partir do momento em que se conhece o outro, ou seja, é na diferença de um sujeito para o outro que se constrói(em) a(s) identidade(s).

Para Olinto (2002, p. 261), a dissolução do sujeito e o abandono de mitos fundadores contribuem para novas formas de emancipação. $\mathrm{O}$ modelo político da diferença questiona o universalismo abstrato da natureza humana (individuum = indiviso) e entende a realidade social "como sistema diferencial composto por uma multiplicidade de discursos que, por seu 
lado, produz uma multiplicidade de posições para o sujeito, marcando o caráter processual de identidades nunca finalizadas" (Loc. cit.).

A identidade e a linguagem refletem um "discurso inconsciente que nos habita e que é constituído por um 'eu' a partir de um outro numa alteridade sem limites” (SCHERER; MORALES; LECLERQ, 2003, p. 24) e que significa intervalos da vida do sujeito e de sua história. O sujeito se reconhece e é reconhecido por sua alteridade. Para Woodward (1997, p. 47, tradução nossa), "a diferença é crucial para classificar sistemas através dos quais significados são produzidos"4. Assim,

esse sujeito não pode dispor de seu deserto sem uma história e é sua história (individual e coletiva) que vai ajudá-lo, vai dar-lhe os meios de povoá-lo, de dispô-lo, de fazê-lo prosperar, de eliminar, preservando sua identidade porque sabemos que todo sujeito é único e singular em seu tempo e em seu espaço. Seu percurso está ligado à sua história de vida e vice-versa. (SCHERER; MORALES; LECLERQ, 2003, p. 24).

De acordo com Woodward (1997, p. 33, tradução nossa), “a identidade do 'forasteiro' é produzida em relação com 'pessoa de dentro"'s. Assim, a ideia de um "eu" isolado no mundo é uma ilusão, porque certamente está enraizado em algum grupo social que compõe uma comunidade (LERAY, 2003, p. 119). Assim, "a língua é o primeiro vetor identitário que testemunha a diversidade sociolinguística das comunidades humanas e a construção identitária não se restringe aos limites de um território, mas inscreve-se numa história mestiça de línguas e de culturas" (Ibid., p. 120).

Nesse trabalho, a identidade, construída e identificada social e culturalmente na alteridade com o outro, é entendida na sua pluralidade, multiplicidade e diversidade de papéis e práticas sociais, transformações, contextos, discursos, textos.

A identidade, então, não é o oposto da diferença, mas depende dela. Nas relações sociais, essas formas de

\footnotetext{
${ }^{4}$ No original: "Difference is central to classificatory systems through which meanings are produced".

${ }^{5}$ No original: "The identity of the 'outsider' is produced in relation to the 'insider"'.
} 
diferença social e simbólica são estabelecidas, pelo menos parcialmente, por meio da operação dos que são conhecidos como sistemas classificatórios. Um sistema classificatório aplica o princípio da diferença a uma população de tal forma que possa dividi-la e todas as suas características em, pelo menos, dois grupos opostos - nós / eles; eu / o outro. (WOODWARD, 1997, p. 29, tradução nossa) ${ }^{6}$.

O sujeito pós-moderno possui identidades sociais individuais (pessoal) e comunitárias (coletiva) também decorrentes do processo de globalização, como pertencente a uma cultura local e global (LASH, 1997). Segundo Giddens (2002, p. 13), "quanto mais a tradição perde seu domínio, e quanto mais a vida diária é reconstituída em termos do jogo dialético entre o local e o global, tanto mais os indivíduos são forçados a escolher um estilo de vida a partir de uma diversidade de opções".

Posto isso, a identidade é fragmentada e definida culturalmente, pois assumimos identidades diferentes em situações diferentes (o ser da fronteira é diferente do ser da capital), em decorrência das novas exigências, mudanças sociais, transformações sociais, novas organizações sociais, novos estilos. Assim, entender a identidade também é compreender o processo de mudança da língua e da sociedade. Tudo isso tem a ver com língua enquanto sociedade multifacetada, variada, bilíngue conforme explica Ivo (2013, p. 104).

Nesse processo cultural e na construção das suas significações, construímos e (re)construímos a nossa identidade sob a influência e à luz da experiência do mundo social, das suas relações, das suas desigualdades e dos diferentes grupos culturais com os quais convivemos.

Esse processo de ida e vinda, de construção e reconstrução, simboliza um período de crise de identidade provocado também pela

\footnotetext{
${ }^{6}$ No original: "Identity, then, is not the opposite of, but depends on, difference. In social relations, these forms of symbolic and social difference are established, at least in part, through the operation of what are called classificatory systems. A classificatory system applies a principle of difference to a population in such a way as to be able to divide them and all their characteristics into at least two, opposing groups - us/them; self/other".
} 
ideologia da globalização que pretende centralizar e homogeneizar tudo e todos. Para Coracini (2003, p. 13), "as diferenças só são respeitadas na medida em que elas garantem a manutenção ou a criação de um novo mercado de consumo". Ainda segundo a autora,

se buscássemos arrolar características, estaríamos estudando a identidade (do lat. idem $=$ mesmo) como o mesmo, idêntico a si, como consciência, razão e não como diferença, descontinuidade, fragmentação. No primeiro caso, estaríamos situando nossas pesquisas numa perspectiva sociológica, que parece mais preocupada em definir a identidade de grupos - nacional, étnica, cultural, sexual, de gênero, profissional... Entretanto, se buscarmos compreender o sujeito como dispersão, sujeito cindido, dividido, atravessado pelo inconsciente, estaremos adotando seja uma perspectiva filosófica (derridiana), seja uma perspectiva discursiva que encontra na psicanálise seu ponto de apoio, voltada sobretudo para a constituição do sujeito do inconsciente que, imerso no discurso - que sempre provém do outro -, é mais falado do que fala (Lacan). (CORACINI, 2003, p. 14-15).

A identidade na modernidade tardia ou pós-colonial também é reflexo de mudanças sociais, culturais, políticas, econômicas e tecnológicas que vivenciamos e que vem trazendo problemas quanto à definição de nacionalidade e territorialidade. De acordo com Lopes e Bastos (2002, p. 14), "vivemos, desse modo, tempos em que há em curso um grande repensar sobre quem somos: os vários veículos da mídia (jornais, revistas, rádio, televisão, internet etc.) deixam clara tal tendência diariamente". E tudo isso é de fundamental importância para compreender o mundo em que vivemos.

A mudança identitária também perpassa pelas questões midiáticas. Em Aceguá, esse polo é voltado para o Brasil, especialmente a TV Globo e as rádios brasileiras, que são bem presentes no cotidiano dos membros da comunidade fronteiriça. Para Giddens (2002, p. 12), "a experiência canalizada pelos meios de comunicação, desde a primeira experiência da escrita, tem influenciado tanto a auto-identidade quanto a organização das relações sociais". 


\section{As identidades e a pós-modernidade}

Para Bauman (2001, p. 17-18), estamos em um período de transição da modernidade sólida para a líquida, dinâmica, com mais mobilidade. Os sólidos são estáveis e os líquidos fluidos:

Os sólidos que estão para ser lançados no cadinho e os que estão derretendo neste momento, o momento da modernidade fluida, são os elos que entrelaçam as escolhas individuais em projetos e ações coletivas - os padrões de comunicação e coordenação entre as políticas de vida conduzidas individualmente, de um lado, e as ações políticas de coletividades humanas, de outro. (Ibid., 2001, p. 12).

Para Bauman (2001), a identidade é única, individual. Portanto, mudar de identidade significa romper com o passado, com determinados vínculos e certas obrigações. Viver em harmonia é utopia de qualquer comunidade, mas, no caso de Aceguá, em certa medida, isso se concretiza bem, porque há uma interação mútua entre ambos os lados da fronteira.

A mudança e a crise da identidade na sociedade pós-moderna declinaram as identidades anteriores, que por tanto tempo guiaram o mundo social. Agora surgem novas identidades que fragmentam o indivíduo moderno, antes visto como um sujeito unificado. A identidade está deslocada, fragmentada e descentrada em várias (HALL, 2005, p. 7).

Em uma mesma comunidade de fala, como é o caso de Aceguá, há variação no uso de nós e a gente e há categoricidade no uso de nós. E há uruguaios que se identificam como uruguaios e brasileiros, e há uruguaios que se identificam apenas como uruguaios. Do lado brasileiro, é mais comum a identidade ser apenas brasileira. Essas identidades não são unificadas ou únicas, mas, muitas vezes, partilhadas em duas, sobretudo para os uruguaios, porque também são os que falam mais as duas línguas, ou seja, ser bilíngue ou monolíngue na fronteira tem relação com a família, o lugar de origem, a(s) língua(s) que fala, além da nacionalidade propriamente dita.

Para Hall (2005, p. 10-13), há três concepções de identidade a partir de três épocas históricas, a saber: 
(i) A identidade do sujeito do iluminismo - indivíduo centrado, unificado, racional. Concepção individualista, biológica, desde o nascimento até a morte;

(ii) A identidade do sujeito sociológico - complexidade do mundo moderno. Concepção interativa da identidade e do eu. Identidade cultural;

(iii) A identidade do sujeito pós-moderno - múltiplas identidades. A identidade é histórica, e não biológica.

O mundo pós-moderno "é de muitas maneiras um mundo único, com um quadro de experiência unitário (por exemplo, em relação aos eixos básicos de tempo e espaço), mas ao mesmo tempo um mundo que cria novas formas de fragmentação e dispersão" (GIDDENS, 2002, p. 12). Assim, este trabalho sobre a fronteira contempla, de certa forma, os sujeitos sociológicos e pós-modernos de Aceguá.

As sociedades modernas ou pós-modernas são, portanto, por definição, sociedades de mudança constante, rápida e permanente. Segundo Hall (2005, p. 17), "as sociedades da modernidade tardia [...] são caracterizadas pela 'diferença'; elas são atravessadas por diferentes divisões e antagonismos sociais que produzem uma variedade de diferentes 'posições de sujeito' - isto é, identidades - para os indivíduos".

A pós-modernidade, modernidade radicalizada, alta modernidade ou modernidade alta e tardia de Giddens (2002) é de ordem pós-tradicional e caracterizada por uma construção reflexiva do eu. As características da modernidade são, portanto, a reflexividade institucional, a reorganização do tempo e espaço e os mecanismos de desencaixe das relações sociais.

A modernidade altera radicalmente a natureza da vida social cotidiana e afeta os aspectos mais pessoais de nossa existência. A modernidade deve ser entendida num nível institucional; mas as transformações introduzidas pelas instituições modernas se entrelaçam de maneira direta com a vida individual, e portanto com o eu. Uma das características distintivas da modernidade, de fato, é a crescente interconexão entre os dois "extremos" da extensão e da intencionalidade: influências globalizantes de um lado e disposições pessoais de outro. (GIDDENS, 2002, p. 9). 
De acordo com Giddens (2002, p. 176), não basta afirmar que o sujeito tem tantos "eus" a depender dos diferentes contextos de interação a que está exposto, já que não é correto "ver a diversidade contextual como simples e inevitavelmente promovendo a fragmentação do eu, quanto mais sua desintegração em 'eus' múltiplos. Essa diversidade também pode, pelo menos em muitas circunstâncias, promover uma integração do eu".

Nesse sentido, a modernidade também produz diferença, exclusão e marginalização, o que pode ocasionar a não realização do eu, afastando a possibilidade da emancipação (Ibid., p. 13). Pode haver unificação (proteção e reconstrução) ou fragmentação, ou seja, uma abertura do mundo para o indivíduo (Ibid., p. 175).

Em Aceguá, não há acirramento suficiente entre os grupos sociais para um confronto nacional forte, mas os conflitos identitários existem em qualquer lugar. As questões históricas nos mostram certa coerência no quesito da integridade e inter-relação entre os povos dessa região fronteiriça. No entanto, na maioria das vezes, "na arena global, identidades nacionais são desafiadas, e lutas entre diferentes comunidades são representadas por identidades nacionais conflitantes - frequentemente com consequências desastrosas" (WOODWARD, 1997, p. 1, tradução nossa) 7 .

A representação cultural do que é ser da fronteira inclui também costumes já considerados brasileiros e uruguaios ao mesmo tempo, como a Semana Farroupilha, por exemplo, porque a identidade é negociada, construída, ratificada, retificada e refutada entre o coletivo e o individual. Por isso, ora a identificação é como uruguaio (e como falante de espanhol), ora como brasileiro (e como falante de português), ao mesmo tempo que há uma tendência também para o mesmo uso do pronome a gente tanto no português uruguaio quanto no português brasileiro da fronteira. Essa tendência se dá até mesmo para que haja a ideia de inclusão de todos os fronteiriços em uma cultura maior, uma comunidade mais geral.

No entanto, socialmente é perceptível as nuances identitárias dos sujeitos, também manifestadas na escolha do pronome de primeira pessoa do plural. O eu uruguaio é associado ao nós, enquanto o eu brasileiro é associado à alternância entre nós e a gente. Posto isso, alguns eus mais

\footnotetext{
${ }^{7}$ No original: "In the global arena, national identities are contested, and struggles between different communities are represented by conflicting national identities - often with disastrous consequences".
} 
arraigados ao Uruguai não utilizam o pronome a gente, e são categóricos no uso de nós.

Nos pronomes de primeira pessoa do plural, a gente é o mais inovador e, portanto, característico de centros mais urbanos. A comunidade de Aceguá tem cerca de $80 \%$ de zona rural, mas os entrevistados são da área urbana, ainda que sofram influências rurais. Para Pagotto (2004, p. 395),

se o processo de variação se inicia na zona urbana e já alcança a zona rural, não necessariamente haverá continuidade nessa direção, pois, uma vez instalado tal processo, a fala da zona rural, mesmo que 'intocada' e 'não afetada', já foi de fato afetada, passa a significar, porque está sob o guarda-chuva dos discursos de identidade.

Isso é característico da confluência de identidade, porque passa para os habitantes uruguaios e brasileiros de uma zona rural, que adquirem traços linguísticos mais urbanos e típicos do português brasileiro. É como se, muitas vezes, os sujeitos buscassem, inconscientemente, identidades mais urbanas e próximas do ideal monolíngue brasileiro.

\section{As identidades discursivas e os significados sociais das variantes}

Pagotto (2004, p. 109) faz uma análise interessante entre a variação linguística como identidade discursiva no sentido de que "as formas variantes fazem falar vozes da comunidade, reunidas no interior da variável linguística". Isso faz parte do sistema heterogêneo linguístico, social e simbólico, no qual as variantes adquirem significados sociais.

Em nosso entendimento, uma análise não anula a outra, mas complementa, em busca dos reais significados das variantes dentro da comunidade em questão - mesmo porque só é possível falar de identidade e fazer outras análises a partir dos resultados estatísticos que nos apontam para essa direção. Dessa forma, além da relação entre as variantes e as categorias sociais, também é possível discutir seus significados sociais.

A geração mais nova, da comunidade de Aceguá como um todo, também é a que mais inova com o uso do pronome a gente, se os categóricos em nós da análise uruguaia são retirados, o que corrobora uma 
aproximação maior com a identidade brasileira. É como se a geração mais jovem estivesse "abrindo mão da cor local como traço fundamental de sua identidade e embarcando na aventura da modernidade" (Ibid., p. 398).

Todavia o processo também não é generalizado para todos os jovens, tendo em vista que os uruguaios bilíngues mais afastados da zona fronteiriça e do contato com o Brasil usam categoricamente o pronome nós, confirmando as diversas formações da identidade. Essa análise só é possível ao olharmos para o indivíduo, no seu comportamento linguístico idioletal, que pode ou não ser reflexo do comportamento linguístico dialetal dos seus pares. Então, segundo Pagotto (2004, p. 399),

\begin{abstract}
A ponta extrema dessa observação são os falantes tomados sob lupa, individualmente. Sob esse último olhar, tanto vamos encontrar, como já vimos, falantes "bem comportados", isto é, refletindo o que se esperaria de sua posição na sociedade, quanto falantes "mal comportados", ou seja, expressando as formas variantes de uma maneira desviante em relação aos grupos aos quais estão rotulados. São estes últimos que nos levam a reafirmar que a entrada de uma forma variante na fala de um indivíduo se dá por uma interpelação de posições, que opera simbolicamente, não sendo, por conseguinte, uma decorrência imediata da vinculação deste ou daquele falante a um dado lugar na estrutura social, em função de sua história, sua escolaridade, sua idade etc. Esta vinculação é, claro, um elemento importante, mas não é o central para explicar a distribuição das formas variantes.
\end{abstract}

O comportamento idioletal também é associado à manutenção de determinada identidade, ou seja, de uma identidade mais uruguaia, associada ao uso de nós. Analisando as variantes do pronome de primeira pessoa do plural, é possível interpretá-las da seguinte maneira:

(i) O pronome a gente seria o pronome da inovação, da aproximação a tudo que é brasileiro, ao que é, de certa forma, estrangeiro, diferente, típico de uma variedade monolíngue. Esse pronome também pode ser interpretado como algo típico do processo de urbanização, modernização, pois representaria os novos tempos, a inter- 
relação na fronteira, o polo econômico, social e político voltado para o Brasil;

(ii) O pronome nós simbolizaria o pronome do conservadorismo tanto no espanhol uruguaio quanto no português brasileiro, mas, como não existe $a$ gente pronominalizado no espanhol, para os bilíngues ou monolíngues uruguaios, a tendência seria preservar cada vez mais sua identidade uruguaia com o uso do pronome nós. É o oposto ao estrangeiro, mas, ao mesmo tempo, como também é um pronome utilizado no Brasil, reflete bem a questão da multiplicidade de identidade, porque o bilíngue uruguaio, muitas vezes, se considera brasileiro e uruguaio, representado por ambas as variantes. O nós simboliza também a questão da natividade, do nacionalismo e da identificação uruguaia.

Os uruguaios que não são bilíngues ou que não usam $a$ gente tendem a se distanciar do Brasil e da identidade brasileira. Já os brasileiros não se identificam como uruguaios em nenhum contexto e as variantes não são típicas do espanhol, uma vez que a gente é utilizado de maneira diferente enquanto, em ambas as línguas, os pronomes nós e nosotros desempenham função semelhante. A diferença, portanto, está exatamente no uso de a gente como terceira pessoa no espanhol e como primeira pessoa do plural no português.

O conceito de identidade é fundamental para o entendimento das mudanças sociais e culturais. No caso de Aceguá, a variabilidade que está em jogo nas variantes de primeira pessoa do plural se deve à mudança linguística com a inserção de $a$ gente no português uruguaio, também instaurada no processo identitário local, e é motivada pelas mudanças sociais vigentes. A escolha de uma variante em detrimento da outra, nos mais variados contextos, está permeada das várias possibilidades da identidade se manifestar no sujeito. Segundo Pagotto (2004, p. 400),

o processo de espraiamento de determinada forma variante é identitário (e por conseguinte, simbólico) o que quer dizer que a relação entre um indivíduo e as categorias sociais a que está vinculado não é direta, isto é, não se trata de uma impressão digital, um carimbo ao qual estariam associados respectivos comportamentos linguísticos. 
O sujeito é multifacetado e, por isso, está imerso em diversas identidades a depender da variante escolhida, porque essa escolha é condicionada linguística e socialmente e os significados sociais são construídos de forma diferente a partir de cada variante em determinado contexto. A identidade é constitutiva do processo de variação e também da relação do sujeito brasileiro com a língua nacional, com a identidade da nação. As formas linguísticas variáveis refletem todo esse jogo discursivo (Ibid., p. 134).

Com relação aos pronomes de primeira pessoa do plural, é interessante notar que, da mesma forma, só sabemos quem somos na interação com o outro, só sabemos o significado social que uma variante tem quando a confrontamos com outra. Para Pagotto (2004, p. 124), "é nisto que consistiria o significado social das variantes: posições de sujeito que se apropriam das formas variantes".

As variantes como portadoras de significação social são reflexos ideológicos e multifacetados das identidades multifacetadas dos falantes. A fala de uma pessoa, portanto, só é reconhecida a partir da existência da fala do outro e da interação entre ambas, o que pode ser ampliado para as variantes (Ibid., p. 133).

O sujeito se utiliza do próprio sistema linguístico para nele inscrever suas marcas de identidade, fruto de ideologias, "que nos fazem 'mesmos' e 'diferentes', segundo a posição constituída: assim, ora se é brasileiro, ora se é de classe média, ora se é nativo, ora se é de fora" (Ibid., p. 117).

Segundo Woodward (1997, p. 1, tradução nossa), "a identidade nos dá a localização no mundo e representa o vínculo entre nós e a sociedade em que vivemos" ${ }^{\text {. O }}$ processo de identidade é algo constitutivo do próprio sujeito, por isso não está relacionado necessariamente à demarcação territorial política ou à nacionalidade. A representação da identidade inclui as práticas de significação, e os sistemas simbólicos pensados como sentidos são produzidos e nos posicionam como sujeitos. A representação como processo cultural estabelece a identidade individual e coletiva, ou seja, diferentes sentidos, contestados e modificados são produzidos por diferentes sistemas simbólicos.

Toda prática de significação que produz sentido envolve relações de poder, inclusive o poder que define quem é incluído ou excluído.

\footnotetext{
${ }^{8}$ No original: "Identity gives us a location in the world and presents the link between us and the society in which we live".
} 
Novas posições e novas identidades dependem também de mudanças econômicas, sociais e culturais a partir da globalização (Ibid., p. 14-16). Ainda assim, em Aceguá se mantém muito da cultura local da fronteira, mas é notório que a abertura para o mais global, mais urbano e mais brasileiro também se manifesta no português uruguaio com a inserção do pronome a gente, uma vez que o polo brasileiro e o ideal monolíngue são mais prestigiados. Ou seja, no caso da identidade, o pronome $a$ gente entra na comunidade uruguaia como sujeito discursivo e não fere a identidade múltipla e fluida dos moradores da fronteira.

\section{Referências}

BAUMAN, Z. Modernidade líquida. Tradução Plínio Dentzien. Rio de Janeiro: Zahar, 2001.

CARVALHO, A. M. Políticas lingüísticas de séculos passados nos dias de hoje: o dilema sobre a educação bilíngüe no norte do Uruguai. Language Problems \& Language Planning, v. 30, n. 2, p. 149-71, 2006.

CORACINI, M. J. Identidade \& discurso: (des)construindo subjetividades. Campinas: UNICAMP; Chapecó: Argos, 2003.

COUTO, H. H. Ecolinguística: estudo das relações entre língua e meio ambiente. Brasília, DF: Thesaurus, 2007.

. Contato português-espanhol na fronteira Brasil-Uruguai. São Paulo: Contexto, 2009a.

. Linguística, ecologia e ecolinguística: contato de línguas. São Paulo: Contexto, 2009b.

DEALTRY, G. F. Memória e esquecimento como formas de construção do imaginário da nação. In: LOPES, L. P. da M.; BASTOS, L. C. Identidades: recortes multi e interdisciplinares. Campinas, SP: Mercado das Letras, 2002. p. 189-201.

ELIZAINCÍN, A.; BEHARES, L. E.; BARRIOS, G. Nos falemo brasilero: dialectos portugueses en el Uruguay. Montevideo: Amesur, 1987.

GIDDENS, A. Modernidade e identidade. Rio de Janeiro: Zahar, 2002.

HAESBAERT, R. Fim dos territórios ou novas territorialidades? In: LOPES, L. P. da M.; BASTOS, L. C. Identidades: recortes multi e interdisciplinares. Campinas, SP: Mercado das Letras, 2002. p. 29-53. 
HALL, S. A identidade cultural na pós-modernidade. Rio de Janeiro: DP e A, 2005.

IVO, E. A. O. O letramento de adultos na empresa: uma formação de legitimar a alienação ou uma questão de sobrevivência? 2013. 232f. Tese (Doutorado em Linguística) - Universidade de Brasília, Brasília, DF, 2013.

LABOV, W. Principles of linguistic change. Volume 2: Social factors. Cambridge: Blackwell Publishers, 2001.

. Padrões sociolinguísticos. Tradução Marcos Bagno, Maria Marta Pereira Scherre, Caroline Rodrigues Cardoso. 1. ed. São Paulo: Parábola, 2008.

LASH, S. Modernização reflexiva: política, tradição e estética na ordem social moderna. In: GIDDENS, A.; ULRICH, G. (Orgs.). A vida em uma sociedade pós-tradicional. São Paulo: Unesp, 1997. p. 73-133.

LERAY, C. A língua como vetor identitário: o caso particular do gaulês na Bretanha. In: CORACINI, M. J. Identidade \& discurso: (des) construindo subjetividades. Campinas: UNICAMP; Chapecó: Argos, 2003. p. 119-36.

LEVY, P. Cibercultura. São Paulo: Ed. 34, 1999.

LOPES, L. P. da M.; BASTOS, L. C. Identidades: recortes multi e interdisciplinares. Campinas, SP: Mercado das Letras, 2002.

OLINTO, H. K. Carteiras de identidade(s) de validade limitada. In: LOPES, L. P. da M.; BASTOS, L. C. Identidades: recortes multi e interdisciplinares. Campinas, SP: Mercado das Letras, 2002. p. 257-276.

PACHECO, Cíntia da Silva. Pressupostos teóricos e procedimentos metodológicos da pesquisa. In. Alternância NÓS e A GENTE no português brasileiro e no português uruguaio da fronteira Brasil-Uruguai (Aceguá). Tese de Doutorado, UnB, 2014.

PAGOTTO, E. G. Variação e (') identidade. Maceió: EDUFAL, 2004.

SANKOFF, D. Variables Rules. In: AMMON, U.; DITTMAR, N.; MATTHEIER, K. J. (Eds.). Sociolinguistics. New York: Academic Press, 1988a. p. 119-27.

. Sociolinguistics and syntactic variation. In: NEWMEYER, F. J. (Ed.). Linguistics: the Cambridge survey. v. 4 (Language: the socio-cultural context). New York: Cambridge University Press, 1988b. p.141-160. 
SANKOFF, D.; TAGLIAMONTE, S. A.; SMITH, E. Goldvarb X: A multivariate analysis application. Toronto: Department of Linguistics; Ottawa: Department of Mathematics, 2005.

SCHERER, A. E.; MORALES, G.; LECLERQ, H. Palavras de intervalo no decorrer da vida ou por uma política imaginária da identidade e da linguagem. In: CORACINI, M. J. Identidade \& discurso: (des) construindo subjetividades. Campinas: UNICAMP; Chapecó: Argos, 2003. p. 23-35.

SCHERRE, M. M. P. S. Speech community. In: BROWN, K. (Ed.). Encyclopedia of Language \& Linguistics. v. 11. 2. ed. Oxford: Elsevier, 2006. p. 716-722.

TRINDADE, I. F. A formação da identidade nacional nas páginas das cartilhas. In: LOPES, L. P. da M.; BASTOS, L. C. Identidades: recortes multi e interdisciplinares. Campinas, SP: Mercado das Letras, 2002. p. 233-254.

UYENO, E. Y. Determinações identitárias do bilinguismo: a eterna promessa da língua materna. In: CORACINI, M. J. Identidade \& discurso: (des)construindo subjetividades. Campinas: UNICAMP; Chapecó: Argos, 2003. p. 37-56.

WEINREICH, U; LABOV, W; HERZOG, M. Fundamentos empíricos para uma teoria da mudança linguística. Tradução Marcos Bagno. São Paulo: Parábola, 2006.

WOODWARD, K. (Org.). Identity and difference: culture, media and identities. London: Sage, 1997.

ZILLES, A. M. S. O que a fala e a escrita nos dizem sobre a avaliação social do uso de a gente? Porto Alegre: Letras de Hoje, v. 42, n. 2, p. 27-44, 2007. 